\title{
Uma Proposta de um Framework para Gerir o Dado como Ativo de Valor nas Empresas de Trânsito
}

\author{
A Proposal fora Framework to Manage the Data as a Valuable Asset in Transit Companies
}

\begin{abstract}
Luciene Maria dos Santos ${ }^{\mathbf{1}}$ (Brcid.org/0000-0003-0606-0293 Andrêza Leite de Alencar ${ }^{2}$ orcid.org/0000-0002-7083-0646
\end{abstract}

\footnotetext{
${ }^{1}$ Escola Politécnica de Pernambuco, Universidade de Pernambuco, Recife, Pernambuco, Brasil.

${ }^{3}$ Bacharelado em Ciência da Computação, Universidade Federal Rural de Pernambuco, Recife, Pernambuco, Brasil.

E-mail do autor principal: Ims2@ecomp.poli.br
}

\section{Resumo}

Um dos grandes desafios das organizações é saber mensurar o valor monetário dos dados. Nos últimos tempos com o surgimento dos grandes e massivos volumes de dados, "Big Data" esta tarefa é cada vez mais desafiadora. Tratar os dados como um ativo de valor auxiliará a organização nas tomadas de decisão de forma mais eficaz e eficiente do contrário a organização poderá está perdendo vantagens e benefícios por não conhecer o potencial verdadeiro do valor monetário dos seus dados. Este trabalho apresenta uma proposta de um framework que auxiliará as empresas a gerir os dados como ativo de valor. Como resultado foi possível monetizar e rentabilizar o valor dos dados e planejar a estimativa de crescimento em uma perspectiva de 5 anos, ponto fundamental que possibilitou que a Instituição não apenas conhecesse o quanto vale o valor de sua informação bem como aprovasse todo planejamento de orçamento financeiro para o ano de 2018 necessário para proteger seu ativo de dados.

Palavras-Chave: Framework; Dados; Ativo; Valor;Big Data;

\begin{abstract}
One of the great challenges of organizations is knowing how to measure the monetary value of data, in recent times with the emergence of large and massive data volumes, "Big Data" this task is increasingly challenging. Treating data as a value asset will help the organization in decision making more effectively and efficiently otherwise the organization may be losing its advantages and benefits by not knowing the true potential of the monetary value of its data. This work shows a proposal for a framework that will help companies to manage data as a valuable asset. As a result, it was possible to monetize and improve the value of the data, planning the growth estimate from a 5 years perspective, as a fundamental point that enabled the Institution, not only to know the value of its information, as well as approving all financial budget planning for the year 2018, required to protect your asset data.
\end{abstract}

Key-words: Framework; Data; Asset; Value; Big Data; 


\section{Introdução}

Nos últimos tempos um termo constante quando se refere a dados é o "Big Data" que são extensos conjuntos de dados, primariamente com as características de volume, variedade, velocidade e/ou variabilidade [2]. Com o amadurecimento do Big Data foram encontradas outras características das quais algumas são: Valor, Veracidade e Visualização.

Com a explosão do Big Data é cada vez mais comum extrair conhecimento dessa quantidade massiva de dados e muito mais desafiador gerar valor de negócio através destes. Outra tarefa desafiadora é saber mensurar o valor monetário do dado tratando-o como ativo intangível, que segundo as normas contábeis um ativo intangível são as contas representativas das aplicações de recursos em bens incorpóreos que contribuirão para a formação do resultado de exercício(s) futuro(s)[10].

Outra maneira para rentabilizar os dados é utilizando-se de práticas de governança de dados adequadas para este fim [14]. Um fator importante a considerar, se a organização não estiver quantificando o valor da informação, é que provavelmente não esteja gerando ou demonstrando seu valor de forma eficaz e suficiente, nem esteja colhendo qualquer outro benefício potencial advindo desta monetização [6].

Diante dessa necessidade surgiu a "infonomics" (disciplina que gerencia e contabiliza o valor da informação com mesmo rigor e formalidade como qualquer outro ativo tradicional que as empresas possuem tais como: ativo financeiro, capital humano, físico (bens e imóveis) e etc.). Cada vez mais cabe às organizações se comportarem como se fossem otimizar a capacidade da informação de gerar valor comercial [4].

É importante mencionar que há um processo natural de maturidade para melhor adotar políticas de governança de dados de acordo com a área de negócio da organização e as atuais circunstâncias desta em relação ao mercado competitivo [14]. Baseado neste processo este trabalho propõe o desenvolvimento de um framework que auxilie a quantificar o valor da informação, para justificar custos e investimentos em infraestrutura de TI, capital humano além de outros custos que proteja e mantenha o seu ativo de dados.

\section{Fundamentação Teórica}

O Dicionário Longman de inglês contemporâneo fornece uma descrição relacionada de um Framework: "um conjunto de fatos, ideias, etc... a partir da qual são desenvolvidas mais ideias ou sobre as quais são baseados" [9].

Frameworks facilitam $\mathrm{o}$ entendimento $\mathrm{e}$ comunicação da estrutura e do relacionamento dentro de um sistema, para um propósito definido, são utilizados como uma forma de traduzir temas complexos em formas que possam ser estudadas e analisadas[17].Suportam 0 processo de tomada de decisão e de resolução de problemas, fornecendo as categorias e representações normalmente em uma linguagem de símbolos[11].

As descrições acima não são mutuamente exclusivas, e parecem combinar com a maioria dos frameworks de gerenciamento existentes. No entanto, uma definição padrão não existe. Os frameworks são cada vez mais utilizados na disciplina de gestão como traduzir questões complexas em um formato simples e analisável [17].

\subsection{O dado como ativo de valor}

Apesar do burburinho em torno do "big data"apenas alguns CIOS e outros executivos de TI informaram que suas organizações estavam conseguindo gerar valor comercial significativo a partir de seus dados [1]. Qual o valor dos seus dados? muitas empresas ainda não sabem a resposta para essa pergunta, mas no futuro as empresas precisarão desenvolver maior expertise na avaliação dos seus ativos de dados.

Ao invés de estudar o valor dos dados no resumo, foram analisados os eventos que provocaram a necessidade de tal avaliação e que pode ser comparado entre as empresas tais eventos. Por tanto foi definido o valor dos dados 
como um composto de três fontes de valor: 1 - 0 ativo, 2- $O$ valor da atividade, 3- $O$ valor esperado ou futuro [17].

Infonomics, expressa o crescente comportamento e a importância da informação como um ativo econômico. Monetiza, gerência e mensura informações como um ativo para vantagem competitiva [7]. O termo Infonomics foi cunhado para transmitir o valor subjacente da informação em termos de produção, demanda de mercado e impacto econômico.

É também a criação do valor moderno para os serviços de informação e aborda a questão de saber se a informação se tornou ou não uma commodity e também mudou a forma de como as empresas devem criar e comercializar suas informações [13].

\section{Objetivo}

Criar um framework de uso comum para auxiliar empresas e organizações de trânsito no suporte à gestão, a estimar uma margem monetária e comercial dos dados da organização, utilizando práticas básicas de fácil acesso e de simples implementação. Este framework a princípio foi aplicado e validado numa instituição pública de trânsito para trabalhos futuros, será empregado em empresas privadas. Este Framework foi desenvolvido inspirado a princípio no trabalho Corporate Governance of Big Data[19]e uma compilação das ideias do demais autores citados nos trabalhos relacionados.

\section{Metodologia}

Este trabalho caracteriza-se como uma pesquisa exploratória baseada na Governança de Dados para a elaboração e aplicação de procedimentos para auxiliar a monetizar ou rentabilizar os dados da organização. A pesquisa para embasamento teórico contou com dados qualitativos por meio de pesquisa a artigos científicos.

Como estratégia desta pesquisa foi utilizado o estudo de caso para validar o processo de implantação deste framework. No contexto desta pesquisa é utilizada a estratégia de estudo de caso único. Baseado nesta estratégia os estudos foram realizados em uma organização apenas.

A Tabela 1 mostra o Fluxo da Metodologia utilizada nesta pesquisa.

Tabela 1 - Fluxo da Metodologia.

\begin{tabular}{l|l}
\hline \multicolumn{1}{c|}{ Tarefa } & \multicolumn{1}{c}{ Descrição } \\
\hline $1-$ & $\begin{array}{l}\text { Consulta exploratória a referências } \\
\text { bibliográficas, artigos científicos, para } \\
\text { o embasamento teórico; }\end{array}$ \\
\hline $2-$ & $\begin{array}{l}\text { Definição dos procedimentos técnicos para } \\
\text { aplicação do objeto deste estudo. Neste caso foi } \\
\text { utilizado um estudo de caso para validação do } \\
\text { framework; }\end{array}$ \\
\hline $3-$ & $\begin{array}{l}\text { Estudo de Caso para implantação e validação do } \\
\text { framework; }\end{array}$ \\
\hline $4-$ & Implantação Framework; \\
\hline $5-$ & \begin{tabular}{l} 
Validação do Framework. \\
\hline
\end{tabular}
\end{tabular}

\section{Framework para Gerir o Dado como Ativo de Valor na Organização}

Este framework é composto por seis etapas que são executadas sequencialmente conforme demonstra a Figura 1.Cada etapa é essencial para se chegar ao valor do dado. Em cada etapa é explicado "como fazer". Nós tópicos seguintes será mostrado o detalhamento de cada etapa do framework. 


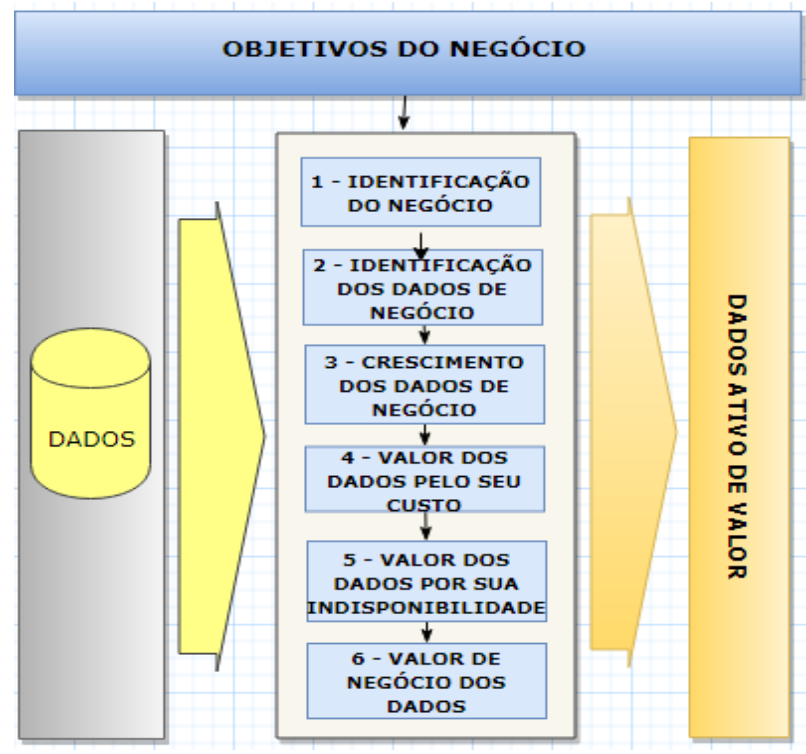

Figura 1 - Representação em Imagem do Framework o Dado como Ativo de Valor - DAV

\section{ETAPA 1 - A Identificação do Negócio}

Esta é a primeira e principal fase para encontrar o valor dos dados da organização, identificar e definir bem o negócio é muito importante. Para isso entrevistas com a alta gestão da empresa e analistas de negócio deixará claro a missão, atividade e objetivo da mesma, a entrada na Figura 1 desta fase é na área de Objetivos do Negócio.

Para empresas que não possuem um setor com especialistas de negócio é importante se deixar claro a atividade da empresa, suas metas e objetivos, identificar bem o que gera receita e o que pode gerar dentro do escopo de atividade da organização, é primordial.

Por exemplo num comércio eletrônico a principal atividade ou negócio da empresa é a venda de produtos por meios eletrônicos que pode ser a clientes finais ou a outras empresas.

\section{ETAPA 2 - A Identificação dosDados de Negócio}

Nesta etapa será feita a identificação e seleção dos dados relevantes para o negócio, ou seja, os dados que geram receita ou que podem ocasionar a perda dela. Aqui nessa fase a área de Negócio juntamente com o DBA ou alguém responsável pelo repositório de dados vai facilitar o acesso e a identificação destas.

Esta etapa é a sequência da Etapa 1 a entrada desta fase se dáà consultas ao repositório de dados. Por exemplo, em um comércio eletrônico pode-se identificar como tabelas de negócio a tabela de CLIENTE, VENDAS, PRODUTO.

\section{ETAPA 3-Crescimento dos Dados de Negócio \\ É importante, independente do porte da} empresa, seja ela pública ou privada, ter um controle efetivo de seus dados de negócio. Esse conhecimento será utilizado como base para os cálculos do valor do dado de negócio e da importância da integridade e planejamento dos storages para mantê-los intactos e disponíveis. Para saber a alocação dos dados a ajuda de um DBA ou de uma pessoa com conhecimento técnico em Banco de Dados se faz necessário.

\section{ETAPA 4 - O Valor do Dado pelo seu Custo}

Neste estudo iremos considerar o valor do custo do dado, o custo total do departamento de Tecnologia da Informação representado na Tabela 2 , pois este responsável pela aquisição, manutenção e disponibilidade dos dados. $\mathrm{Na}$ verdade, o termo "custo" é utilizado, porém agrega valor à informação pois preserva e protege o valor da mesma.

O que compõe o custo do setor de Tecnologia da Informação compreende Custos Fixos (mão de obra + infraestrutura) e as licenças de uso de software e equipamentos se for o caso. A Equação (1) representa o Custo Médio Anual:

$$
\text { CustoMedioAnual }=\text { CustoMensal } / 12
$$

Tabela 2 - Custo Mensal do Departamento de Tecnologia da Informação.

\begin{tabular}{l|l}
\multicolumn{1}{c|}{ Custos } & IndicadorCusto \\
\hline $\begin{array}{l}\text { Custos Fixos e Variáveis } \\
\text { (Folha de Pagamento + Treinamentos + } \\
\begin{array}{l}\text { Compra de Equipamentos para } \\
\text { o departamento de Tecnologia da } \\
\text { Informação }\end{array}\end{array}$ & A \\
\hline $\begin{array}{l}\text { Licenças de Software } \\
\text { Licenças de Hardware } \\
\text { caso existam }\end{array}$ & B \\
\hline Total & C \\
\hline
\end{tabular}

$\begin{array}{clll}\text { Custos Mensais do Departamento } & \text { de } \\ \text { Tecnologia da Informação }+ \text { Compra de }\end{array}$


equipamentos para o departamento de Tecnologia da Informação.

$A=$ Folha de Pagamento + Treinamentos ou algum custo eventual com o capital humano

$B$ = Licenças de Software tais como licenças do(s) banco(s) de dados e suporte + licenças de software de desenvolvimento e etc.

$\mathrm{C}=$ Licenças de Hardware caso existam tais como licenças com equipamentos físicos aluguel de computadores, blader, Storages e etc.

ETAPA 5 - Valor do Dado baseado em sua Indisponibilidade

É muito comum as empresas perderem receita e/ou responderem a processos jurídicos devido à ausência, indisponibilidade e/ou erro na aquisição e manutenção do seu ativo de dados.

Existe outros tipos de prejuízos nesta etapa, normalmente a grande maioria das empresas já sofreram algum prejuízo por negligenciar uma política de controle, segurança e disponibilidade da informação. É comum as grandes empresas perderem valor na bolsa de valores ou valor de mercado.

\section{ETAPA 6 - Valor de Negócio do Dado}

Valor de Negócio do Dado ou Valor da Informação será utilizado nesta fase as tabelas de negócio já identificadas na etapa 2 as que geram receita ou que geram perda de receita. Nesta fase também iremos utilizar a identificação do negócio que foi feita na Etapa 1.

Podemos citar um exemplo de um comércio eletrônico onde a identificação do negócio que no nosso framework fica na Etapa 1 é Comércio Virtual ou Comércio não presencial as tabelas de negócio que no nosso framework fica na etapa 2 são normalmente identificadas como tabela de Cliente, Vendas ou Faturamento.

A empresa também pode além do comércio virtual ter uma outra atividade de negócio como por exemplo a empresa presta serviços de consultoria isso outro negócio então poderia se calcular o valor de negócio do comércio virtual e da prestação de serviços pois são faturamentos distintos. É preciso considerar um tempo médio de receita pois, apenas um ano não reflete muitas vezes a realidade do quanto a empresa de fato fatura.

\section{Estudo de Caso e suas Principais Características}

O primeiro passo para iniciar uma pesquisa adotando a estratégia de estudo de caso é a definição do objetivo e da abordagem que normalmente são: qualitativa, quantitativa ou uma combinação das duas. O estudo de caso tem como propósito reunir informações detalhadas e sistemáticas sobre um fenômeno [12].

O estudo de caso é uma investigação empírica que investiga um fenômeno contemporâneo dentro de seu contexto da vida real [21] adequado quando as circunstâncias são complexas e podem mudar, quando as condições que dizem respeito não foram encontradas antes, quando as situações são altamente politizadas e onde existem muitos interessados [8].

Para aplicar e validar este trabalho foi utilizada a técnica de estudo de caso exploratório em uma única empresa. Seguindo as diretrizes propostas por Runeson et al. [15]. Este estudo possui uma abordagem qualitativa com estudos exploratórios, estudos exploratórios são todos aqueles que buscam descobrir ideias e soluções [16], abordando cada evento e situação de cada etapa nele proposto.

Este framework baseia-se nas características e objetivos dos frameworks de gerenciamento e gestão com a particularidade de envolver a área de negócio e ter como escopo empresas e organizações de trânsito.

\subsection{Dados e Características da Organização deste Trabalho}

A organização selecionada para este estudo é em uma organização pública de trânsito do estado de Pernambuco e envolverá as áreas de negócio e de banco de dados. Num primeiro momento será identificado o negócio ou atividade principal da organização.

Serão utilizados como amostragem deste estudo de caso para análise, os dados contidos nas tabelas de negócio do banco de dados da instituição coletadas via consultas SQL. Neste estudo a atividades principais da organização é de Serviços e Fiscalização de Trânsito para a população.

http: / /dx.doi.org/10.25286/repa.v3i3.962 
A arrecadação é feita através destas duas atividades. Estas informações foram levantadas com as áreas de negócio e em consultas a missão e objetivo do órgão.

Também foi identificado uma divisão para os serviços pois possuem taxas de cobrança diferentes $e$ as regras de negócio para o funcionamento delas também é diferente. Portanto estão divididas as áreas em Habilitação e Veículo, diferente de um comércio eletrônico ou um comércio tradicional pois basicamente 0 negócio é baseado no valor do produto.

As tabelas de dados de negócio neste caso que são identificadas na Etapa 2 do framework, as mais relevantes são: Tabela de USUARIO, TAXASSERVICOS, VEICULO, SERVICO, na grande maioria das empresas a tabela de USUARIO é a tabela de CLIENTE e a tabela de VENDAS, PRODUTOS são as tabelas de negócio.

No capítulo a seguir será descrito de forma detalhada todas as etapas do framework definido.

\subsection{Framework (DAV) aplicado e validado no DETRAN-PE}

A seguir a aplicação deste framework na Instituição Pública de Trânsito DETRAN-PE.

\section{ETAPA 1 - A Identificação do Negócio}

Nesta etapa foi identificado o negócio ou atividades de negócio do DETRAN-PE com entrevistasaos gestores das áreas de negócio. Foi identificado dois grandes pilares que norteia a área de negócio desta instituição que são elas: Área de Habilitação que arrecada com serviços de habilitação de trânsito para a população. Área de Veículo que arrecada com serviços de veículo, Licenciamento de Veículo e Infrações de Trânsito.

\section{ETAPA 2 - A Identificação dosDados de Negócio}

Os dados de negócio nesta etapa foram identificados com consultas às áreas de negócio com suporte do DBA. Para área de Habilitação foi identificado a tabela de USUARIO e na área de Veículo a tabela de VEICULO. Estas são as tabelas chave onde nasce toda arrecadação.
ETAPA 3 - Crescimento dos Dados de Negócio

O Código de Trânsito Brasileiro não impõe uma limitação de idade máxima para possuir uma habilitação que é revista com exames médicos em média entre 2 a 5 anos, portanto neste estudo consideramos os usuários habilitados até 70 anos de idade o que representa $94 \%$ da tabela de USUARIO os outros $6 \%$ consideramos outliers visto que o acesso dos mesmos aos serviços de condutores são inexpressivos, estas considerações foram feitas para área de Habilitação.

Para área de Veículo consideramos os veículos ativos, ou seja, que a situação esteja normal para abertura de serviços e cobranças de taxas e licenciamentos. Os veículos ativos representam $78 \%$ da base da tabela de VEICULO os $22 \%$ restantes são considerados veículos com situação que não geram serviços.

O Quadro 1 representa o Percentual Médio de Crescimento Anual dos Dados das Tabelas de Negócio.

Quadro 1 - Percentual Médio de Crescimento Anual dos Dados das Tabelas de Negócio

\begin{tabular}{|l|l|}
\hline $\begin{array}{l}\text { Percentual Médio de Crescimento Anual dos Dados } \\
\text { das Tabelas de Negócio }\end{array}$ \\
\hline $\begin{array}{l}\text { Área de } \\
\text { Habilitação } \\
\text { (USUÁRIO) }\end{array}$ & $7,26 \%$ \\
\hline $\begin{array}{l}\text { Área de Veículo } \\
\text { (VEÍCULO) }\end{array}$ & $6,27 \%$ \\
\hline
\end{tabular}

ETAPA 4 - O Valor do Dado pelo seu Custo

Abaixo na Tabela 3 segue os custos do Departamento de Tecnologia da Informação do DETRAN-PE estimados para o ano de 2018.

Tabela 3 - Custo Mensal do Departamento de Tecnologia da Informação para o ano de 2018.

\begin{tabular}{|c|c|}
\hline Custos & IndicadorCusto \\
\hline $\begin{array}{l}\text { Custos Fixos e } \\
\text { Variáveis } \\
\text { (Contratos de Pessoal } \\
+ \text { Treinamentos + } \\
\text { Compra de } \\
\text { Equipamentos para } \\
\text { o departamento de } \\
\text { Tecnologia da } \\
\text { Informação }\end{array}$ & $\begin{array}{l}\mathrm{R} \$ 25.452 .613,33 \text { Ano } \\
\mathrm{R} \$ 2.121 .051,11 \text { Mês }\end{array}$ \\
\hline
\end{tabular}




\begin{tabular}{l|lr}
\hline Licenças de Software & $\mathrm{R} \$$ & $9.696 .588,81$ Ano \\
& $\mathrm{R} \$$ & $808.049,07$ Mês \\
\hline Licenças de Hardware & $\mathrm{R} \$$ & $13.463 .504,42$ Ano \\
caso existam & $\mathrm{R} \$$ & $1.121 .958,70$ Mês \\
\hline Total & R\$ 48.612.706,56 \\
\hline
\end{tabular}

ETAPA 5 - Valor do Dado baseado em sua Indisponibilidade

Neste estudo de caso um exemplo de perda de receita por falta ou indisponibilidade da informação se deu da seguinte forma:

Por consultas à base de dados de Infração, a infração mais cometida nos últimos cinco anos foi: Transitar em velocidade superior à máxima permitida para o local em até $20 \%$ (vinte por cento), considerada uma infração Média que acarreta 4 pontos na Carteira Nacional de Habilitação o valor desta multa é de R\$130,16.

A média mensal dos últimos cinco anos desta infração dá um valor de: 35.468,38 x R\$130,16 $=\mathrm{R} \$ 4.616 .564,77$ em arrecadação mês só da infração mais cometida, este valor é deixado de arrecadar no mês caso a organização não consiga coletar os dados das multas dos sensores e agentes de trânsito ou simplesmente não conseguir entregá-las aos destinatários.

\section{Cálculo da Média Mensal}

A média aritmética da quantidade de infração mais cometida nos últimos 5 anos. Isto foi feito através de consulta a base de dados.

Quadro 2 - Quantidade da Infração mais cometida por ano.

\begin{tabular}{|l|l|}
\hline \multicolumn{2}{|l|}{ AnoQuantidade de Infrações } \\
\hline 2013 & 165.566 \\
\hline 2014 & 305.315 \\
\hline 2015 & 490.680 \\
\hline 2016 & 638.597 \\
\hline 2017 & 527.945 \\
\hline
\end{tabular}

Na Equação (2) têm-se a Média dos últimos 5 anos da infração mais cometida. $=\frac{(165.566+305.315+490.680+638.597+527.945)}{5}$

Média Anual $=425.620,60$

Na Equação (3) têm-se a Média Mensal da Infração mais cometida nos últimos 5 anos.

Média Mensal $=$ Média Anual $/ 12$

Média Mensal $=425.620,60 / 12$

Média Mensal $=35.468,38$

\section{ETAPA 6 - Valor deNegócio do Dado}

A seguir o cálculo do valor do negócio baseado em nosso estudo de caso que possui mais de um tipo de negócio.

\section{Negócio Área Habilitação}

Arrecadação com Serviços

Tabela 3 - Demonstrativo da Média de Arrecadação com Serviços dos Últimos 5 Anos.

\begin{tabular}{l|l}
\hline \multicolumn{1}{c|}{ Média Arrecadação } & Indicador Média \\
\hline $\begin{array}{l}\text { Média de Arrecadação } \\
\text { com Serviços últimos } 5 \\
\text { anos }\end{array}$ & A \\
\hline $\begin{array}{l}\text { Média Estimada } \\
\text { Arrecadação com } \\
\text { Serviços últimos 5 } \\
\text { anos }\end{array}$ & \\
\hline
\end{tabular}

Na Equação (4) temos a Média de Arrecadação com Serviços últimos 5 anos:

$A=$ Média de Arrecadação com Serviços dos Últimos 5 anos $=(\Sigma$ das Arrecadações dos últimos 5 anos)/5

Na Equação (5) temos a Média Estimada de Arrecadação com Serviços últimos 5 anos:

$B=$ Média Estimada de Arrecadação com Serviços últimos 5 anos = Média de Arrecadação dos Últimos 5 anos + (Média de Arrecadação dos Últimos 5 anos * Percentual Médio de Crescimento Anual da tabela de Negócio).

http: / / dx.doi.org/10.25286/repa.v3i3.962 
Média Estimada de Arrecadação com Serviços últimos 5 anos $=A+(A * 7,26 \%)$

\section{Negócio Área Veículo}

Arrecadação com Serviços, com Licenciamento e Infrações

Tabela 4 - Demonstrativo da Média de Arrecadação com Serviços, com Licenciamento e Infrações dos Últimos 5 Anos.

\begin{tabular}{l|l}
\hline \multicolumn{1}{c|}{ Média Arrecadação } & \multicolumn{1}{c}{$\begin{array}{c}\text { Indicador } \\
\text { Média }\end{array}$} \\
\hline $\begin{array}{l}\text { Média de Arrecadação com Serviços, } \\
\text { Licenciamento, Infrações últimos } 5 \text { anos }\end{array}$ & W \\
\hline $\begin{array}{l}\text { Média Estimada Arrecadação com Serviços, } \\
\text { Licenciamento e Infrações últimos } 5 \text { anos }\end{array}$ & $\mathrm{X}$ \\
\hline $\begin{array}{l}\text { Média de Arrecadação com Serviços, } \\
\text { Licenciamento e Infrações últimos } 5 \text { anos }\end{array}$ & $\mathrm{Y}$ \\
\hline $\begin{array}{l}\text { Média Estimada Arrecadação com Serviços, } \\
\text { Licenciamento e Infrações últimos } 5 \text { anos }\end{array}$ & $\mathrm{Z}$ \\
\hline
\end{tabular}

Na Equação (6) é demonstrada a Média de Arrecadação com Serviços dos Últimos 5 anos:

$W$ = Média de Arrecadação com Serviços dos Últimos 5 anos $=(\Sigma$ das Arrecadações dos últimos 5 anos)/5

$\mathrm{Na}$ Equação (7) é demonstrada a Média Estimada de Arrecadação com Serviços últimos 5 anos:

$X=$ Média Estimada de Arrecadação com Serviços últimos 5 anos = Média de Arrecadação dos Últimos 5 anos + (Média de Arrecadação com Serviços dos Últimos 5 anos * Percentual Médio de Crescimento Anual da tabela de Negócio)

Média Estimada de Arrecadação com Serviços últimos 5 anos $=\mathrm{W}+(\mathrm{W} * 6,27 \%)$

Na Equação (8) é demonstrada a Média de Arrecadação com Licenciamento e Infrações dos Últimos 5 anos:

$\mathrm{Y}=$ Média de Arrecadação com Licenciamento e Infrações dos Últimos 5 anos $=\left(\begin{array}{ll}\Sigma & \text { das }\end{array}\right.$ Arrecadações dos últimos 5 anos)/5

82
$\mathrm{Na}$ Equação (9) é demonstrada a Média Estimada de Arrecadação com Licenciamento e Infrações últimos 5 anos:

$Z$ = Média Estimada de Arrecadação com Licenciamento e Infrações últimos 5 anos = Média de Arrecadação dos Últimos 5 anos + (Média de Arrecadação com Licenciamento e Infrações dos Últimos 5 anos * Percentual Médio de Crescimento Anual da tabela de Negócio)

Média Estimada de Arrecadação com Licenciamento e Infrações últimos 5 anos $=\mathrm{Y}+$ $(Y * 6,27 \%)$

Na Equação (10) é demonstrado o Valor Total dos Dados da Instituição:

Valor Total dos Dados da Instituição $=\Sigma(A, W, Y)$

\section{Trabalhos Relacionados}

No trabalho de Pauline Glikman e Nicolas Glady[5] um Processo de 6 etapas é proposto para calcular o valor dos dados da empresa onde o dado é avaliado sob quatro perspectivas: pelos acionistas, ou seja, o quanto os acionistas de mercado estão dispostos a pagar pelos dados de clientes de uma empresa que toma decisões através dos dados, pela empresa considerando as receitas geradas pelos seus clientes, por avaliações do próprio cliente individualmente provocando questões do tipo até que ponto valorizamos nossos próprios dados, pela internet um mercado mundial de dados onde leva-se em questão a tendência do mercado de monetizar os dados oriundos da mesma.

o presente estudo difere do estudo supracitado porque é a proposta de um framework para auxiliar a calcular o valor dos dados. É também aplicado em um estudo de caso e mostrado os resultados obtidos.

Infonomia e o valor da informação na economia digital [3]observa que o valor da informação atende as normas de contabilidade, porém este ativo ainda não está sendo declarado em nenhum balanço contábil empresarial. Os 
resultados deste estudo expandem a noção da infonomia e que esta, tem como objetivo mostrar os métodos de contabilidade bem como os fatores que afetam os ativos da informação e seu valor econômico.

O presente estudo tem por objetivo uma proposta de um framework para auxiliar a calcular o valor dos dados o que difere do estudo anterior "Infonomia e o valor da informação na economia digital" que tem por principal objetivo mostrar que o valor dos dados atende as normas de contabilidade.

O trabalho de Todd Tramba [20] apresenta um processo de 6 etapas para calcular o valor dos dados da empresa que são: 1-O valor do negócio, 2-O valor dos dados do cliente, 3-Definir o valor da empresa sem os dados, 4- Custo para reposição dos dados de negócio, 5- Tempo é dinheiro, 6- Tempo empregado para repor dados perdidos.

Apesar do estudo anterior relacionar seis etapas para se calcular o valor dos dados da empresa o que difere deste estudo que tem como proposta para calcular o valor dos dados, um framework que auxilie neste objetivo e a validação deste num estudo de caso.

O trabalho de Garifova L.F [3] apresenta um método que auxilia a contabilidade da informação. O autor relaciona como etapas deste método: 0 valor da informação (VI), O valor da informação para o negócio (VIB), Perda do valor da informação (LIV), Valor da produtividade da informação (VIP), Valor econômico da informação (EVI), Valor de mercado da informação (MVI) e cada etapa acima relacionada é calculada através de fórmulas e variáveis.

O que difere este estudo do estudo supracitado é que além do framework que auxilia a chegar no valor dos dados da organização é aplicado para validá-lo num estudo de caso e cada etapa para se obter o valor dos dados é bem distinta de um trabalho para o outro.

Obs.: Uma característica comum a todos os trabalhos relacionados é que nenhum deles cita a sua aplicação na prática nem mesmo utilizando um estudo de caso para tal experimento.

\subsection{Resumos Esquemáticos dos Trabalhos Relacionados}

A Tabela 5 relaciona um resumo esquemático dos trabalhos relacionados.

Tabela 5 - Resumo Esquemático dos Trabalhos Relacionados (continua)

\begin{tabular}{|c|c|c|c|}
\hline Trabalho & Propósito & $\begin{array}{l}\text { Aplicabilidade } \\
\text { do Estudo } \\
\text { para } \\
\text { sua Avaliação }\end{array}$ & \\
\hline $\begin{array}{l}\text { Pauline } \\
\text { Glikman, } \\
\text { Nicolas } \\
\text { Glady [5] }\end{array}$ & $\begin{array}{l}\text { Avaliação do } \\
\text { valor dos } \\
\text { dados por } \\
\text { quatro } \\
\text { perspectivas } \\
\text { (pelos } \\
\text { acionistas, } \\
\text { pela própria } \\
\text { empresa, } \\
\text { pelos } \\
\text { próprios } \\
\text { usuários, } \\
\text { pela Internet } \\
\text { um mercado } \\
\text { mundial de } \\
\text { dados) }\end{array}$ & $\begin{array}{l}\text { Os Autores não } \\
\text { citam aplicação } \\
\text { do estudo. }\end{array}$ & $\begin{array}{l}\text { Os autores } \\
\text { não } \\
\text { apresentam } \\
\text { conclusão e } \\
\text { resultados do } \\
\text { estudo. }\end{array}$ \\
\hline
\end{tabular}

Tabela 5 - Resumo Esquemático dos Trabalhos Relacionados (continua)

\begin{tabular}{l|l|l|l}
\hline Trabalho & Propósito & $\begin{array}{l}\text { Aplicabilidade } \\
\text { do Estudo } \\
\text { para } \\
\text { sua Avaliação }\end{array}$ & \\
\hline Garifova L.F & $\begin{array}{l}\text { O autor } \\
\text { observou } \\
\text { que } \\
\text { o valor da } \\
\text { informação } \\
\text { atende as } \\
\text { normas de } \\
\text { contabilidade } \\
\text { e chegou à } \\
\text { conclusão } \\
\text { este ativo } \\
\text { ainda não } \\
\text { está sendo } \\
\text { declarado } \\
\text { em nenhum } \\
\text { balanço } \\
\text { contábil } \\
\text { empresarial. }\end{array}$ & $\begin{array}{l}\text { O autor } \\
\text { sugere que } \\
\text { sejam } \\
\text { feitos mais } \\
\text { estudos por } \\
\text { organizações } \\
\text { de vários } \\
\text { setores } \\
\text { distintos. }\end{array}$ \\
\hline $\begin{array}{l}\text { Um processo } \\
\text { de 6 passos } \\
\text { para calcular } \\
\text { o valor dos } \\
\text { dados da } \\
\text { empresa. }\end{array}$ & $\begin{array}{l}\text { O autor não } \\
\text { cita aplicação } \\
\text { do estudo. }\end{array}$ & $\begin{array}{l}\text { O autor não } \\
\text { apresenta } \\
\text { conclusão e } \\
\text { resultados do } \\
\text { estudo. }\end{array}$ \\
\hline Todd & $\begin{array}{l}\text { Um método } \\
\text { que auxilia a }\end{array}$ & $\begin{array}{l}\text { O autor não } \\
\text { cita aplicação }\end{array}$ & $\begin{array}{l}\text { O autor não } \\
\text { cita aplicação }\end{array}$ \\
\hline Lamba[20y, & \\
\hline Gartner [6] & \\
\hline
\end{tabular}

http: / /dx.doi.org/10.25286/repa.v3i3.962 


\begin{tabular}{|c|c|c|c|}
\hline & $\begin{array}{l}\text { contabilidade } \\
\text { da } \\
\text { informação. }\end{array}$ & $\begin{array}{l}\text { do estudo, mas } \\
\text { sugere que } \\
\text { sejam feitos } \\
\text { mais estudos } \\
\text { por } \\
\text { organizações } \\
\text { de vários } \\
\text { setores } \\
\text { distintos. }\end{array}$ & $\begin{array}{l}\text { do estudo } \\
\text { além do que } \\
\text { se propõe o } \\
\text { próprio } \\
\text { método } \\
\text { desenvolvido. }\end{array}$ \\
\hline $\begin{array}{l}\text { Framework } \\
\text { o Dado } \\
\text { como Ativo } \\
\text { de } \\
\text { Valor-DAV }\end{array}$ & $\begin{array}{l}\text { Um } \\
\text { framework } \\
\text { para gerir os } \\
\text { dados como } \\
\text { ativo de } \\
\text { valor.. }\end{array}$ & $\begin{array}{l}\text { O estudo foi } \\
\text { validado } \\
\text { mediante } \\
\text { estudo de caso } \\
\text { único em } \\
\text { instituição } \\
\text { pública de } \\
\text { trânsito. }\end{array}$ & $\begin{array}{l}\text { Resultado } \\
\text { comparativo } \\
\text { entre o valor } \\
\text { do dado e o } \\
\text { valor do } \\
\text { hardware. }\end{array}$ \\
\hline
\end{tabular}

\section{Conclusões e Resultados}

Este presente estudo possibilitou 0 desenvolvimento de um framework para auxiliar a monetizar o valor dos dados, além disso, permitiu sua aplicabilidade em uma instituição pública de trânsito. Em seu desenvolvimento foi possível conhecer de fato a importância dos dados de negócio para a organização, permitiu que a organização conhecesse o valor dos seus dados.

Depois de concluído, o seu resultado foi útil para aprovação de orçamentos necessários para a manutenção e proteção dos ativos de dados, finalmente a organização teve conhecimento de que o orçamento para 2018 para proteção de sua informação representa apenas $1 \%$ em relação ao valor monetário total dos dados, encontrado após aplicação deste framework.

A Tabela 6 demonstra a estimativa de crescimento em 5 anos do Valor dos Dados por Área de Negócio - Habilitação. Este percentual $6,27 \%$ foi encontrado na Etapa 3.

Tabela 6 - Estimativa de crescimento do Valor dos Dados em 5 anos - Negócio de Habilitação.

\begin{tabular}{l|l}
\hline \multicolumn{1}{c|}{ Ano } & \multicolumn{1}{c}{ Valor dos Dados } \\
\hline 2018 & $\mathrm{R} \$ 93.967 .743,67$ \\
\hline 2019 & $\mathrm{R} \$ 99.859 .521,20$ \\
\hline 2020 & $\mathrm{R} \$ 106.120 .713,18$ \\
\hline 2021 & $\mathrm{R} \$ 112.774 .481,89$ \\
\hline 2022 & $\mathrm{R} \$ 119.845 .441,91$ \\
\hline
\end{tabular}

Cálculo da Estimativa de crescimento da Área de Negócio de Habilitação expressa na Equação (11):

Ano Seguinte $=$ Valor dos Dados $* 6,27 \%+$ Ano

Exemplo: $\quad 93.967 .743,67 \quad * \quad 6,27 \% \quad+$ $93.967 .743,67$

A Tabela 7 demonstra a estimativa de crescimento em 5 anos do Valor dos Dados por Área de Negócio- Veículo. Este percentual 7,26\% foi encontrado na Etapa 3.

Tabela 7 - Estimativa de crescimento do Valor dos Dados em 5 anos - Negócio de Veículo.

\begin{tabular}{l|l}
\hline \multicolumn{1}{c|}{ Ano } & \multicolumn{1}{c}{ Valor dos Dados } \\
\hline 2018 & $\mathrm{R} \$ 2.901 .319 .483,51$ \\
\hline 2019 & $\mathrm{R} \$ 3.111 .955 .278,01$ \\
\hline 2020 & $\mathrm{R} \$ 3.337 .883 .231,19$ \\
\hline 2021 & $\mathrm{R} \$ 3.580 .213 .553,78$ \\
\hline 2022 & $\mathrm{R} \$ 3.840 .137 .057,78$ \\
\hline
\end{tabular}

Cálculo da Estimativa de crescimento da Área de Negócio de Veículo expressa na Equação (12):

Ano Seguinte $=$ Valor dos Dados $* 7,26 \%+$ Ano

Exemplo: $\quad 2.901 .319 .483,51 * 7,26 \%+$ 2.901.319.483,51

A Figura 2 e a Figura 3 representam o Valor da Informação aplicando o percentual médio de crescimento dos dados denegócio, ou seja, representa as médias estimadas de arrecadação numa perspectiva em cinco anos que corresponde aos valores contidos nas Tabelas 6 e 7, esta informação foi utilizada para o planejamento dos próximos orçamentos e foi fundamental para aprovação de todos os recursos financeiros pendentes de aprovação. 


\section{Área de Negócio Habilitação}

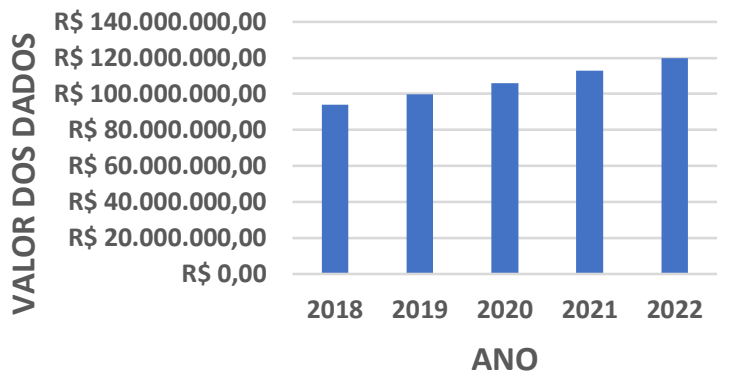

Figura 2:Crescimento Médio Anual Área de Negócio de Habilitação perspectiva em 5 anos

\section{Área de Negócio Veículo}

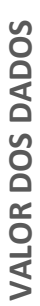

R\$ 5.000.000.000,00

$R \$ 4.000 .000 .000,00$
$R \$ 3.000 .000 .000,00$
$R \$ 2.000 .000 .000,00$
$R \$ 1.000 .000 .000,00$

$\mathrm{R} \$ \mathbf{0 , 0 0}$

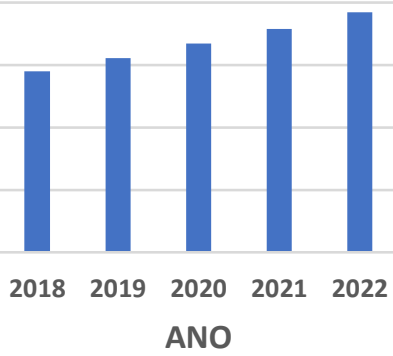

Figura 3:Crescimento Médio Anual Área de Negócio de Veículo perspectiva em 5 anos

A Tabela 8 mostra o Valor Total dos Dados encontrado na última etapa deste Framework e o Plano de Orçamento Anual (despesas para manter e proteger o Ativo de Dados) para o Ano de 2018 o custo para manter e proteger os dados representa $1 \%$ do seu valor.

Tabela 8 - Valor Total dos Dado X Orçamento Anual para o Ano de 2018

\begin{tabular}{l|c}
\hline \multicolumn{1}{c|}{ Descrição } & Valor \\
\hline Valor Total dos Dados & $\mathrm{R} \$ 4.087 .304 .268,13$ \\
\hline $\begin{array}{l}\text { Plano de Orçamento } \\
\text { Anual 2018 }\end{array}$ & $\mathrm{R} \$ 48.206 .901,23$ \\
\hline $\begin{array}{l}\text { Plano de Orçamento } \\
\text { Ano 2018 em relação } \\
\text { ao Valor dos Dados }\end{array}$ & $\mathbf{0 , 0 1 1 7 9 4 3 0 2 ~} \mathbf{1 \%}$ \\
\hline
\end{tabular}

A Figura 4 mostra o Valor Total dos Dados aplicando o fator de crescimento dos dados de negócio numa perspectiva em 5 anos.

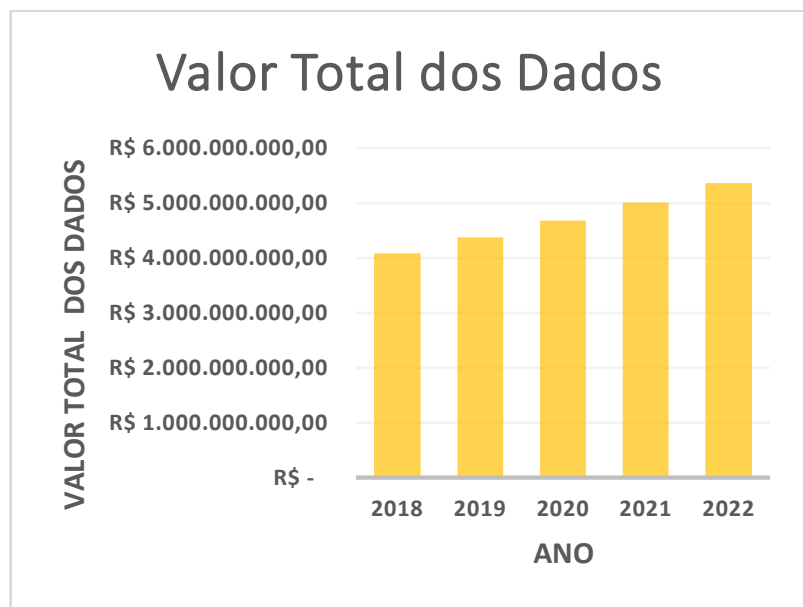

Figura 4 - Valor Total dos Dados uma perspectiva em 5 anos.

\section{Referências}

[1] BEATH, Cynthia et al. Finding value in the information explosion.MIT Sloan Management Review, v. 53, n. 4, p. 18, 2012.

[2] GRECY, Nance; CHANG, Wo. Big Data Interoperability Framework: volume 1, definitions. Massachusetts: NIST, 2018.

Disponível em:

<https://nvlpubs.nist.gov/nistpubs/SpecialPublica tions/NIST.SP.1500-1.pdf>. Acesso em: $10 \mathrm{abr}$. 2018 as $09 \mathrm{~h} 15 \mathrm{~min}$.

[3] GARIFOVA, L. F. Infonomics and the Value of Information in the Digital Economy. Procedia economics and finance, v. 23, p. $738-743$, 2015. Disponível em:<https://www.sciencedirect.com/science/artic le/pii/S2212567115004232 >. Acesso em: 13 de abril 2018 as 20 h02 min.

[4] GARTNER. IT Glossary: Infonomics. Disponível em: <https://www.gartner.com/itglossary/infonomics>. Acesso em: 13 abr. 2018 as $10 \mathrm{~h} 45 \mathrm{~min}$.

[5] GILKMAN, Pauline; GLADY, Nicolas. What's the Value of your Data, Techcrunch, 2015.

http: / /dx.doi.org/10.25286/repa.v3i3.962 
Disponível em:

<https://techcrunch.com/2015/10/13/whats-thevalue-of-your-data/>. Acesso em: 13 abr. 2018 $15 \mathrm{~h} 37 \mathrm{~min}$

[6] LANEY, Doug. Infonomics: the economics of information and principles of information asset management. In: INFORMATION QUALITY

INDUSTRY SYMPOSIUM, 5., 2011, Massachusetts. Proceedings...Massachusetts: MIT, 2011. p. 2. Disponível em:

<http://mitiq.mit.edu/IQIS/Documents/CDOIQS 201177/Papers/05_01_7A-1_Laney.pdf>. Acesso em: 14 abr. 2018 as $14 \mathrm{~h} 16 \mathrm{~min}$.

[7] LANEY, Douglas. Infonomics: How to Monetize, Manage, and Measure Information as an Asset for Competitive Advantage. Reino Unido: Routledge, 2017.

[8] LLEWELLYN, Sue; NORTHCOTT, Deryl. The "singular view" in management case studies. Qualitative Research in Organizations and Management: An International Journal, v. 2, n. 3, p. 194-207, 2007.

[9] LONGMAN, Dictionary of America English (HardCover). 5 ed. Lognman Dictionaries, 2014.

[10] LUDÍCIBUS, S. et al. Contabilidade Introdutória. 11 ed. São Paulo: Editora Atlas, 2010.

[11] ODEH, Mohammed; KAMM, Richard. Bridging the gap between business models and system models.Information and Software Technology, v. 45, n. 15, p. 1053-1060, 2003.

[12] РАТTОМ, M. G. Qualitative Research and Evaluation Methods. 3 ed. Thousand Oaks, CA: Sage, 2002.

[13] REGAZZI, John J. Infonomics and Values Creation in the New Business of Free. Hershey: IGI Global, 2013.
[14] ROMER, Rafael. Empresas Brasileiras têm prejuízo de US\$26 bi com perda de dados. Canaltec, 4 dez. 2014. Disponível em: <https://canaltech.com.br/seguranca/Empresasbrasileiras-tem-prejuizo-de-US-26-bi-com-perdade-dados-aponta-estudo/>. Acesso em: 13 abr. 2018 as 12 h04min.

[15] RUNESON, Per et al. Case Study Research in Software Engineering: Guidelines and Examples. New Jersey: John Wiley \& Sons, 2012.

[16] SELLTIZ, C.; JAHODA, M.; DEUTSCH, M. Métodos de Pesquisa nas Relações Sociais. São Paulo: EDUSP, 1974.

[17] SHEHABUDDEEN, N., PROBERT, D., PHAAL, R. Representing and approaching complex management issues: part 1 - role and definition. Working Paper. Institute for Manufacturing, University of Cambridge, 2000.

[18] SHORT, James; TODD, Steve. What's Your Data worth? MIT Sloan Management Review, v. 58, n. 3, p. 17, 2017. Disponível em: $<$ https://sloanreview.mit.edu/article/whats-yourdata-worth/> Acesso em: 5 jul. 2018 as $11 \mathrm{~h} 55 \mathrm{~min}$.

[19] TALLON, Paul P. Corporate governance of big data: Perspectives on value, risk, and cost.Computer, v. 46, n. 6, p. 32-38, 2013.

[20] TRAMBA, Todd, 2014. A 6 Step process to Calculate the Value of Company Date. Teclink, July 2014. Disponível em:

$<$ http://www.tccohio.com/blog/a-six-stepprocess-to-calculate-the-value-of-companydata >. Acesso em: 14 abr. 2018 as 11 h19min.

[21] YIN, Robert K. Estudo de caso:

planejamento e métodos. 3 ed.Porto Alegre: Bookman, 2005. 